\title{
An Empirical Study of Applying E-mail Exchange to College English Learners' Writing
}

\author{
Jiaxin Xing \\ College English Department, Qufu Normal University, Qufu, China
}

\begin{abstract}
The present study is to find the effect of E-mail exchange activity on the students' writing proficiency. It aims to answer the following questions: (1) How does the E-mail exchange influence the students' writing? (2) What is the students' attitude toward using E-mail in English learning? (3) What problems do the students encounter during their E-mail exchange activity? After the E-mail exchange for an academic semester, the data was collected and analyzed with both quantitative and qualitative methods. The results indicate that E-mail exchange activity promotes the students' writing proficiency a lot. Generally speaking, the students hold a positive attitude toward the activity, and both their learning motivation and self-confidence get improved. Their problems are mainly lack of vocabulary, low response, and cultural difference, etc.
\end{abstract}

Index Terms—E-mail exchange, college English, writing teaching

\section{INTRODUCTION}

Writing is a difficult skill for native speakers and nonnative speakers alike. It is a complex process, because writers must balance multiple issues such as content, organization, purpose, audience, diction, vocabulary, and mechanics (Rass, 2001). English writing is especially difficult for Chinese students not only because they are expected to create written products that demonstrate mastery of all of the above elements in a new language but also because they have different cultural and thinking patterns contrasted with the English native speakers. Among the various forms of facilitating language teaching and learning via the Internet, E-mail has been so far the most popular and useful tool. In China, applying the E-mail into English writing teaching is still a relatively new field due to the late access to the Internet. Even though there are heated discussions about the effects of E-mail on language learning in China, there is not much empirical evidence that supports its potentials. A few researchers have conducted some empirical studies to explore the potentials of E-mail. However, many of them admitted that there was much room for improvement due to some practical difficulties. Besides, the studies nearly all concern English majors, neglecting the majority of English learners in China. In order to find more evidence to support the potential of E-mail application in the English teaching in China, the present study is conducted with a group of non-English majors in a university.

\section{LITERATURE REVIEW}

With the development of computer technology, using E-mail to facilitate language teaching started to gain more and more attention of scholars abroad in the 1990s. Since then a large amount of literature has been worked out. Though there has not been convincing experimental evidence on the use of computer technology to improve language skills in all areas, the majority of the studies indicate positive attitudes of students toward technology use.

Janda (1995) conducts a series of E-mail activities to help his EFL students build up collaborative writing skills. The activities include interpreting and discussing statistics from graphs and charts; explaining, interpreting and discussing comic strips and other humor; preparing for an oral presentation by laying out and discussing each student's main points and arguments; and solving a literary jigsaw in which students have different amounts of information. These activities provide rich opportunities for students to gather together and engage in the writing collaboratively.

Belisle (1996) discusses student and teacher benefits of using E-mail in EFL writing instruction. The argument of the author goes that over a network, using E-mail and sharing files, students have the chance to collaborate and work together with other classmates, peers, and teachers. Therefore, acting in the electronic community can help learners create, analyze, and produce information and ideas more easily and efficiently. Through this increased electronic access to the world around them, Belisle claims, students' social awareness and confidence increases.

Choi (1998) reports on E-mail exchange project in Korea. Both teachers and students report improvements in children's reading skills, consolidation of vocabulary and increased motivation. The article concludes by emphasizing the importance of planning and preparation in conducting a key pal exchange and stresses the pivotal role played by the external moderator in such an undertaking.

Compared with the studies abroad, researches in China are relatively far slower and fewer. Gu (1998) claims that four interaction interfaces of E-mail should be given equal attention for successful E-mail assisted English teaching. In 1997, she and her co-researcher, David Catterick organized an E-mail key pal project accomplished collaboratively by 
graduate students. Students worked together to complete their term paper. The project is intrinsically motivating for them because of the meaningful tasks, real sense of audience and improving of computer literacy. Students' imagination, creativity and cooperative ability are put into full play.

Pan (2000) conducted an experiment on E-mail-assisted teaching programs. He attempted to find whether it was effective and feasible to facilitate culture teaching via E-mail. To guide the students, topics like lifestyle, food and clothing, love, marriage and family life were suggested by the instructor. The findings showed that students took a positive attitude towards the activity, and it not only widened students' horizon, but increased their expressing ability.

Shang (2007) conducted a study in Taiwan, which focused on examining the overall effect of using E-mail on the improvement of writing performance in aspects of syntactic complexity, grammatical accuracy and lexical density, as well as investigating the relation between the number of E-mail exchanges and writing performance. By applying qualitative and quantitative research methods, the major finding demonstrated that students made improvements on syntactic complexity and grammatical accuracy. An increase in lexical density, however, was not observed.

In recent years, the information technology develops at a higher speed than ever, and it is no longer so hard as before for students to get access to the Internet. Students are required to attend the computer course and this renders them enough knowledge necessary throughout the E-mail exchange activity. All these provide researchers with favorable conditions to conduct further research. The purpose of the study is to find out whether the E-mail exchange activity can contribute to College English writing teaching. It will also investigate the students' motivation and confidence in English writing, and their attitude toward the E-mail exchange activity.

\section{Methodology}

\section{A. Research Questions}

(1) How does the E-mail exchange influence students' writing? Is there any statistically significant difference between the writing performance of the experimental group (EG) and that of the control group (CG)?

(2) What problems do students encounter in the E-mail exchange activity? What are the advantages the activity brings to the students?

(3) What are students' attitudes toward using E-mail in English learning?

\section{B. Subjects}

The subjects in the study were 74 non-English majors in a University in China. They were of two naturally occurring classes with each class 37 students. They were at the first year's study and taught by the same instructor. The EG was the E-mail group, and the CG was the non-E-mail group. All the subjects had learned English for at least seven years and most have some basic knowledge about computer technology. The E-mail group were arranged to communicate with students in the USA. via E-mail throughout the Autumn Semester. The E-mail communication was conducted in English and lasted for four months. Throughout the activity, it was assured that both two groups got the same encouragement, and the only difference was that the EG wrote in E-mail while the CG not.

\section{Instruments}

Three data collection instruments used in the study include the pre- and post-writing tests assessing students' writing ability, a questionnaire for surveying students' attitudes to E-mail exchange activity, students' E-mail messages and answers in the exit interview.

a. Writing Tests. The writing tests aimed to measure student writing ability before and after the E-mail exchange activity. Therefore, a pre-test and post-test were conducted to determine the effectiveness of this activity. The topics in the two tests were the same. Students were asked to write an article about the topic "the craze of going abroad for further study", which might prompt them to express a lot.

b. Questionnaire. The questionnaire was used to elicit students' attitudes toward their experience in the E-mail exchange activity and their perceptions about the advantages and problems of using E-mail. It consisted of 20 questions in all. In the questionnaire, subjects were required to answer on a five point scale: 1=strongly disagree; $2=$ disagree; $3=$ uncertain; 4=agree; $5=$ strongly agree. Students were informed that the survey was for the purpose of research, and was not to be used to evaluate their performance.

c. Interview. To confirm the subjects' answers to the questions in questionnaire, an in-depth, interview was conducted with 10 randomly selected students in the experimental group. The interview went on in a comfortable atmosphere and students were free in expressing their opinions.

\section{Procedure}

When the EG and CG were decided, members in EG were asked to get their E-mail addresses ready for the E-mail exchange activity. Then, those who did not know how to send and receive E-mails were instructed by their classmates. After that, a list of the subjects' E-mail addresses was produced. The researcher sent all the subjects a letter and got replies, which means that their E-mail channel worked well. In this way, all the subjects got ready for the activity.

a. Obtaining the E-pals

Obtaining the appropriate E-pals plays a very important role in the activity. There are several ways generally, like 
asking foreign friends to assist you in finding some native speakers; giving the subjects some pen pal websites and letting them choose by themselves according to their own interest; or having a discussion with the foreign teacher directly with the help of the Internet. Nowadays, there are a number of international pen pal projects on line. The following are usually taken as some of the most useful ones:

http://www.iecc.org/

http://www.interpals.net/

http://www.studentsoftheworld.info/

http://www.penpalworld.com/

http://penpalsnow.com/

http://www.epals.com/

http://penpals.net/

However, some of the previous studies recommended that among all the ways the best is for the teacher to team up with a class in a different country directly $(\mathrm{Gu}, 1998)$. Therefore, in the present study the researcher posted pieces of messages on several popular pen pal websites seeking one American class as partner. Finally, a class from the Atlee High school in Richmond, Virginia, the USA was chosen. They were found to be suitable for the activity because the American teacher was interested in this activity and the number of the students was same as that of ours. Besides, they were at their second year's study in high school. They were supposed to be good partners considering that their English proficiency might be a little higher than the EG members. After some negotiation, an agreement was reached that the researcher sent the list of Chinese students' E-mail addresses to American teacher, and then the American students would start the E-mail exchange activity.

b. Establishing Communication

In the following week, the subjects in the EG all felt excited to receive the E-mails from the American students. The exchange started with their self-introductions. But after several days, a few students sent the researcher E-mails complaining that their letters were returned from Richmond as undeliverable ones. The researcher tried to send massages to those addresses and received the same response as the students did. Fortunately, E-mail communication with the American teacher functioned well, and the problem was discussed with him. The website server in Richmond was suspected to be the cause of the problem, or maybe the foreign E-mail system firewall was too picky, but no exact reason was found. To continue the activity, the American teacher suggested his students trying their E-mail exchange with another address. In this way the problem got solved and the communication went smoothly.

c. Conducting the Study

After the subjects started their E-mail exchange with American students, they were required to write at least one letter a week to their e-pals and forward it to the researcher so that their performance in the activity can be controlled. If it contains something private, the subjects can keep them to themselves. The researcher suggested some topics, and an agreement was reached with American teacher that students would be encouraged to talk about the suggested topics in their massages in the activity. Nevertheless, the content of the E-mail messages was not graded for fear of giving them too much pressure, and the choice of topics was left to student discretion. The proposed topics are as follows:

my dream; leisure activities; the Internet and the world; the Olympics and me; on-line romance; air pollution/environmental protection; love, success and wealth; What does the USA./China attract you most? China and the world; my favorite occupation; the person I like most; an memorable trip; music in our life; cultural shock; the effects of exercise on our health; The world is becoming warmer, your comments on this?; What do you think of going abroad to get further study?; Dating is popular with students on campus, what is your opinion?; What attitudes should we take to money?; Is there friendship between boys and girls?; How to face success and failure?

At the end of the semester, the students in both experimental and control groups took an identical writing test (post-test), they were supposed to write an article with roughly 120 to 150 words in 30 minutes on the topic "the craze of going abroad for further study" as they did in pre-test. Independent samples T-test was carried out to see whether there was significant difference between the scores obtained for both two groups. And an attitude survey was conducted to the experimental group to know the E-mail group's attitude toward the activity and perception. Finally, some of the subjects in the experimental group were interviewed, in which their opinions of participating in the activity were asked.

\section{E. Data Collection}

The pre-test and post-test were conducted to 74 students in the experimental and control classes in the beginning and end of the semester respectively. At the end of the project, students in the experimental class were given the questionnaire asking them to comment on various aspects of the activity. Among the 37 copies distributed, 37 were returned, 36 were valid. All subjects answered the questionnaires within 10 minutes in classroom and their responses counted for the investigations. At the end of the autumn semester, 10 students in the experimental class were interviewed to check the reliability of their answers to the questionnaire, and to give students an opportunity to provide more in-depth responses.

\section{F. Data Analysis}

The results were analyzed by using SPSS17.0. Both quantitative and qualitative research methods were used to analyze the data. First, students' compositions were scored by two teachers according to the rating scale by Heaton 
(2000). Correlation analyses were performed between the two sets of scores. The degree to which two such sets of scores varied was estimated by calculating a correlation coefficient. The correlation coefficient has a high value of 0.934, which was significant at the 0.01 levels. The students' names and classes in composition paper were concealed. The evaluation of writing performance was based on the scores of the pre- and post-writings by the students. Then independent T-tests was performed to examine if there was a significant difference between the means for the experimental and control groups in the pre- and post-writings; paired sample T-test was performed to see whether the means in pre-test and post-test for the E-mail group differed significantly.

\section{REsults}

\section{A. A Comparison of the Writing Performance of EG and CG in Both Pre-writing and Post-writing}

In the beginning of the semester, an independent sample T-test was conducted to check the difference of pre-test scores between the two groups. The mean score of the EG is 79, CG is 78.46, the mean difference is 0.54 . The p-value (0.699>0.05) showed that the writing performance between the two groups was not significantly different.

The same T-test was administered to check the difference of post-test scores between these two groups (see table 1). The mean of the EG is 83.19, while the CG is 81.05, thus the difference is 2.13514 . The p-value $(0.043<0.05)$ of the T-test in the table indicated that significant difference was found between the post-test scores.

TABLE 1

THE RESULT OF INDEPENDENT SAMPLE T-TEST OF TWO GROUPS' MEANS IN THE POST-WRITING

\begin{tabular}{|c|c|c|c|c|c|c|c|}
\hline & & \multicolumn{4}{|c|}{ Levene's Test for Equality of variances } & \multicolumn{2}{|c|}{ T-test for equality of means } \\
\hline & & $\mathrm{F}$ & sig & $\mathrm{T}$ & df & Sig.(2-tailed) & M difference \\
\hline \multirow[t]{2}{*}{ Post-test } & $\begin{array}{l}\text { Equal variances } \\
\text { assumed }\end{array}$ & .022 & .883 & 2.058 & 72 & $.043^{*}$ & 2.13514 \\
\hline & $\begin{array}{l}\text { Equal variances not } \\
\text { assumed }\end{array}$ & & & 2.058 & 71.98 & .043 & 2.13513 \\
\hline
\end{tabular}

In the questionnaire, four questions were designed to survey the subjects' perception on the E-mail exchange activity; they were mainly about the usefulness of the activity. The results are illustrated in the following table.

TABLE 2

THE RESULTS OF THE QUESTIONS ON STUDENTS' PERCEPTION OF USEFULNESS

\begin{tabular}{|c|c|c|c|c|c|}
\hline Survey questions & $\min$ & $\max$ & $\mathrm{M}$ & SD & $\mathrm{N}$ \\
\hline 15. This kind of E-mail exchange may promote my English writing performance. & 3 & 5 & 4.03 & 0.774 & 36 \\
\hline 16. I think exchanging E-mails in English is a good way to improve writing ability. & 3 & 5 & 4.33 & 0.717 & 36 \\
\hline 17. I feel my English writing ability gets improved after the activity. & 2 & 5 & 3.47 & 0.774 & 36 \\
\hline 18. I am satisfied with this kind of E-pal correspondence. & 1 & 5 & 3.94 & 1.068 & 36 \\
\hline
\end{tabular}

Note. Min=minimum $\max =$ maximum $\mathrm{M}=$ mean $\mathrm{SD}=$ standard deviation $\mathrm{N}=$ number of the subjects

The subjects rated high the statements "This kind of E-mail exchange may promote my English writing performance." "I think exchanging E-mails in English is a good way to improve writing ability." with the mean scores 4.03 and 4.33 respectively. They rated fairly high the statement 17 and 18, which means that most of them felt their writing proficiency got improved and they were satisfied with the activity.

\section{B. The EG Members'Attitudes toward Using E-mail in English Learning}

EFL students will be more successful in their attempts to write in a second language when they possess positive attitudes toward second language learning in general. In the questionnaire, the subjects were asked to rate their attitudes toward the activity on a five-point scale.

TABLE 3

THE RESULTS OF THE QUESTIONS ON STUDENTS' ATTITUDES

\begin{tabular}{|c|c|c|c|c|c|}
\hline Survey questions & $\min$ & $\max$ & M & SD & $\mathrm{N}$ \\
\hline 1. I think this kind of E-mail exchange is very interesting. & 3 & 5 & 4.58 & 0.554 & 36 \\
\hline 2. I am glad to know foreign E-pals. & 4 & 5 & 4.69 & 0.467 & 36 \\
\hline 3. I enjoy participating in this kind of activity. & 3 & 5 & 4.44 & 0.607 & 36 \\
\hline 19. I'll continue the E-mail exchange with my E-pal after the semester. & 2 & 5 & 4.22 & 0.866 & 36 \\
\hline 20. If possible, I'll suggest my friends communicating with foreigners via E-mail. & 3 & 5 & 4.25 & 0.692 & 36 \\
\hline
\end{tabular}

As can be seen from the table, the subjects in the E-mail group had positive attitudes toward the E-mail exchange, for the mean scores of all the questions in this category are above 4.00, which means that most subjects agree with the statements of the questions. Among the five questions in the category, the first three are about their belief; the last two are about their behaviors. In the above table, the mean score for question number 19 and 20 is 4.22 and 4.25 respectively, this means that the majority of the subjects intended to continue E-mail exchange after the activity was over, and they would advise their friends to conduct this kind of exchange. 


\section{The Changes of EG Students' Confidence and Motivation in English Learning before and after E-mail Exchange}

In the present study, questions 11-14 of the questionnaire were designed to discover the students' confidence and motivation in English writing. The following table shows the results:

TABLE 4

THE RESULTS OF THE QUESTIONS ON STUDENTS' CONFIDENCE AND MOTIVATION

\begin{tabular}{|l|l|l|l|l|l|}
\hline Survey questions & $\min$ & $\max$ & $\mathrm{M}$ & $\mathrm{SD}$ & $\mathrm{N}$ \\
\hline 11. This kind of E-pal correspondence promoted my learner autonomy. & 2 & 5 & 3.61 & 0.803 & 36 \\
\hline 12. I have more confidence in English writing after the activity. & 2 & 5 & 3.50 & 0.845 & 36 \\
\hline 13. I become more active to write in English now. & 2 & 5 & 3.44 & 0.809 & 36 \\
\hline 14. The activity enhanced my interest on English and motivation to learn it. & 2 & 5 & 3.83 & 0.737 & 36 \\
\hline
\end{tabular}

The subjects rated statement 14 "The activity enhanced my interest on English and motivation to learn it." with the highest score 3.83, and statement 11 followed with the score 3.61. This indicated the subjects got more interest and a higher motivation in English learning. And they believed their autonomy in learning got enhanced. The scores of the statements 12 and 13 were a bit lower than 11 and 14, while they were still fairly high.

\section{The Problems EG Students Encountered during Their E-mail Exchange and the Advantages They Perceived}

Question 4-6 are supposed to survey the subjects perceived advantages and 7-10 about the problems (see table 5).

TABLE 5

THE RESULTS OF THE QUESTIONS ON THE PROBLEMS AND ADVANTAGES IN THE ACTIVITY

\begin{tabular}{|c|c|c|c|c|c|}
\hline Survey questions & $\min$ & $\max$ & $\mathrm{M}$ & SD & $\mathrm{N}$ \\
\hline 4. Communicating with my E-pal makes me feel my writings become meaningful. & 2 & 5 & 4.25 & 0.841 & 36 \\
\hline 5. I know more about the foreign culture after the activity. & 1 & 5 & 3.75 & 1.079 & 36 \\
\hline $\begin{array}{l}\text { 6. Writing with E-mail makes me feel relaxed, not so nervous as writing in the traditional } \\
\text { way. }\end{array}$ & 2 & 5 & 3.86 & 1.046 & 36 \\
\hline $\begin{array}{l}\text { 7. Sometimes I can not understand my E-pal's letters well because of the culture } \\
\text { differences. }\end{array}$ & 1 & 5 & 2.97 & 1.158 & 36 \\
\hline 8. Generally speaking, my E-pal's low responses make me feel upset. & 1 & 5 & 3.00 & 1.493 & 36 \\
\hline 9. I can not express myself very well in the E-mail. & 2 & 5 & 3.08 & 0.806 & 36 \\
\hline 10. When communicating with my partner, I often feel my vocabulary is not sufficient. & 2 & 5 & 4.42 & 0.692 & 36 \\
\hline
\end{tabular}

The table showed us well some of the perceived advantages and encountered problems for the subjects. The subjects rated the statements about the advantages comparatively high. The high scores indicate that most of the subjects agree with the statements. Particularly for the statement 4, the mean was as high as 4.25 . This means that nearly all the subjects believed E-mail exchange made their writings meaningful. As for the problems, statement 10 got the highest mean 4.42; the other three were about 3.

\section{E. The Effects of E-mail Exchange on the Students'English Writing}

In the E-mail exchange with the American students, the subjects must get some influence from their partners. While their general writing proficiency might get improved, some changes might also occur to their aspects of writing. In the present study, the five parts - content, organization, vocabulary, language use and mechanics were included and compared to find the possible changes. The following is the result of the paired sample T-test of the sores of these five parts in the pre-test and post-test writing for the EG (table 6).

TABLE 6

THE RESULTS OF PAIRED SAMPLE T-TEST OF THE SUBENTRIES' MEANS FOR EG'S PRE- AND POST-WRITINGS

\begin{tabular}{l|l|l|l|l}
\hline & $M$ & $t$ & $d f$ & sig.(2-tailed) \\
\hline Con 1-con 2 & -1.08108 & -4.097 & 36 & $.000^{* *}$ \\
\hline Org 1-org 2 & -.58459 & -2.876 & 36 & $.007^{* *}$ \\
\hline Voc 1-voc 2 & -1.10811 & -5.240 & 36 & $.000^{* *}$ \\
\hline Lan 1-lan 2 & -1.18919 & -4.263 & 36 & $.000^{* *}$ \\
\hline Mech 1-mech2 & -.05405 & -.442 & 36 & .661 \\
\hline
\end{tabular}

The paired sample statistics showed that the mean scores of all the five parts got increased after the E-mail exchange. And the T-test indicated that the differences of all the parts were significant except mechanics. In the parts of content, vocabulary and language, we had full confidence to claim that significant differences were found.

\section{DiscUSSION}

\section{A. The Improvement of Writing Scores}

Significant difference was found in the writing performance of the two groups in post-writing, which means that the E-mail exchange activity contributed to the improvement of writing proficiency of the subjects in EG. In the present study, many factors may contribute to the improvement of the subjects' writing proficiency. The positive attitudes 
toward writing via E-mail might be one of the factors, for they can contribute to improving their writing skills by increasing their willingness to write and revise the writings. In the exit interview, many subjects claimed that they enjoyed the E-mail exchange partly because they had a lot in common to share. Another possible factor is the reading of their E-pals' letters. Reading experience may be as beneficial as or more beneficial than writing practice to develop writing ability. The more they read, the more they become familiar with the vocabulary, idiom, sentence patterns, organizational flow and cultural assumptions of native speakers of the language (Raimes, 1983). Exchanging E-mails with native speakers provided the students opportunities of exposure to authentic language. Many students in the interview admitted that they learned a lot from the foreign partners, including language itself.

In the E-mail exchange activity, students are now actually writing for a real-life audience and not just for the teacher. This has proved to be a huge stimulus for students to make writing a fun rather than a boring activity. Thus, students become more willing to put their heart into writing, ideas spring into their mind, and they are so engrossed in communicating that they focus on the content and organization of their E-mails. Besides, they paid much attention to the content and language because they believed good writing might attract their partners easily. When they write to their partner, they are likely to be very careful because they want to communicate effectively. Maybe these were the reasons for the progress in the parts of content, organization, language and vocabulary. In the exit interview, some subjects mentioned like this: "she (the partner) is always earnest about my E-mail. And she is happy to point out my mistakes in my E-mail." "I learned a lot from her. I can learn many new words and ..."

The reason for the non-improvement of mechanics in students' writing possibly lies in the style difference between E-mail language and printing language. Compared with the printing language, the language in E-mail is usually not so formal. The participants, especially American students, usually do not refine on their letters. The writing style of them is relaxed, spontaneous and conversational in nature, with many starts and stops, incomplete sentences. Therefore, the requirement of language accuracy would be played down. The following E-mail from the American student can be taken for example:

American student A's E-mail:

I will definitely ask Ivy tomorrow =)

So, I have a lot of homework to get done, so I cannot type much.

Random questions: do you plan to visit US sometime in the future? And have you been to places outside of China?

Have a wonderful weekend!

Besides the quantitative analysis, EG members' writings were analyzed qualitatively as a supplement to see the changes of their writing performance. Generally speaking, the students' post-writings were more substantive and closely organized. And also there were more complex constructions. Many students' pre-writings were loosely organized, and the expression was not fluent at all. In some students' samples the ideas were even confused or disconnected. Even though some students attempted to use some complex constructions in the writing, they made serious grammatical mistakes and the meanings of sentences were therefore obscured. The following are from the students' pre-writing samples:

- I can not tell the craze of going abroad to obtain further study is good or bad.

- And that there are a few people don't know whether it is better to go abroad or not.

- But there are also many people don't think so.

- So there are many people have different views.

- My idea is that when we get an idea of our own culture, then we'll better to select others.

- In my opinion, on one hand, in many aspects, such as learning foreign languages, majoring the good subjects in the best foreign school, you go abroad to get a best environment for you study.

In the post-writing, the students paid more attention to the text organization and word choice. Therefore, their expressions were much more fluent than in the pre-writing. In addition, they used more effective complex constructions in their writings, which means that they had a better mastery of sentence construction rules. And also, their expressions became more native-like. The following may serve as evidence:

- As the globalization has been a trend, the world is becoming much more closely related. At the same time, the number of Chinese students going abroad to further their study is multiplying.

- Therefore, it's better to make good preparation before you make a decision to go abroad. Otherwise you may fail to achieve your goals.

- In my opinion, we should take everything into consideration.

- The reason of such phenomenon is that many students believe that studying abroad can make them more popular when they go back China and look for jobs.

- Nowadays, there are more and more students going abroad for further study.

- However, each coin has two sides. Studying abroad also has some drawbacks.

To have a better look at the vocabulary using, an analysis was conducted to the two randomly selected students' preand post-writings with the tool of Range. The results are as follows ${ }^{1}$ :

\footnotetext{
${ }^{1}$ Due to space limit, the result of analysis of student B's writings were not demonstrated in tables here.
} 
TABLE 7

THE RESULT OF THE ANALYSIS OF STUDENT A'S PRE-WRITING

\begin{tabular}{llll}
\hline WORDLIST & TOKENS $/ \%^{2}$ & TYPES/\% & FAMILIES \\
\hline one & $108 / 87.10$ & $69 / 86.25$ & 63 \\
two & $7 / 5.65$ & $5 / 6.25$ & 5 \\
three & $5 / 4.03$ & $2 / 2.50$ & 2 \\
not in the lists & $4 / 3.23$ & $4 / 5.00$ & $? ? ? ? ?$ \\
Total & 124 & 80 & 70 \\
\hline
\end{tabular}

TABLE 7

THE RESULT OF THE ANALYSIS OF STUDENT A'S POST-WRITING

\begin{tabular}{llll}
\hline WORDLIST & TOKENS/\% & TYPES/\% & FAMILIES \\
\hline one & $140 / 86.42$ & $85 / 85.00$ & 75 \\
two & $13 / 8.02$ & $12 / 12.00$ & 10 \\
three & $9 / 5.56$ & $3 / 3.00$ & 3 \\
not in the lists & $0 / 0.00$ & $0 / 0.00$ & $? ? ? ? ?$ \\
Total & 162 & 100 & 88 \\
\hline
\end{tabular}

Comparing the above two tables, we can find that in the later one, student A had more to say and a better use of vocabulary. In the post-writing, the total number is 162 words, while only 124 in the early one. Among all the words used, $8.02 \%$ and $5.56 \%$ fall into the wordlist two and three in the post-writing, while only $5.65 \%$ and $4.03 \%$ in the pre-writing. And higher percentage of word types in post-writing fall into wordlist two than that in pre-writing. Table 6 also shows that $3.23 \%$ of the vocabulary used in student A's pre-writing falls into the class "not in the lists". Here it should be noted that the four words are not included in the wordlists because they were misspelled. They are: foergn, lifes, ourself, varities. Also student B had more to express on the topic in the later writing than the early one. In the pre-writing, the word number is only 109, which is lower than the required. And also the lower percentage of tokens and types in wordlist one and higher percentage in wordlist three in B's post-writing indicate well that the student had a better mastery of vocabulary. $(83.11 \%<85.32 \% ; 6.76 \%>5.50 \% ; 78.79 \%<87.50 \% ; 6.06 \%>2.78 \%)$ Still the percentage of word types in word list two in B's post-writing is much higher than that in pre-writing. $(13.13 \%>9.72 \%)$

\section{B. Positive Attitude towards E-mail Exchange Activity}

It was found that the subjects took a positive attitude towards the E-mail exchange activity. Nearly all the subjects showed great interest in the E-mail exchange. Even most of them would advise their friends to begin this kind of correspondence. As was mentioned in the above, positive attitude towards the activity might partly account for the improvement of the writing proficiency. A Chinese proverb says: Interest is the best teacher. When people are interested in something, they learn it quickly and efficiently.

Students' positive attitudes can also be demonstrated in the numbers of E-mails they wrote. They were expected to write one letter a week in the beginning of the activity; however, many of them wrote more than the expected number. The highest number even amounted to 20. This showed that they were eager to exchange E-mails with the American students. More insight into students' attitudes toward this activity comes from the comments given by the students in the interview. When asked "What do you think of this kind of E-mail exchange activity", "Will you keep the relationship with your E-pal and continue to write to him or her?" Some students gave such general comments as:

- I feel the E-mail exchange activity is good. It's fun to write with my partner.

- I got a lot of fun of writing to my foreign friend, I really enjoy it

- I think it is really very interesting to write to a foreign e-pal. I think I will get more and more in the activity, so I will continue to write affirmatively.

- The answer is sure. I will keep the relationship with my foreign friend and continue to write to him.

- Yes, I can not find a reason why I do not keep a relationship with her.

- There is no doubt that it's a lot of fun writing to my E-pal. My E-pal is a very good girl, she had many topics and we chatted happily. I now put her in my list of best friends though I haven't met her.

Another point deserving noting here is that a number of the subjects continued to write their pen pals when the new semester began even it was no longer required. All these served as good evidence to show that the students were active in communicating with the native speakers.

\section{Higher Motivation and More Confidence}

Most subjects in EG agreed that the E-mail exchange activity enhanced their autonomy, confidence and motivation. Choi (1998), Jogan et al. (2001), Gu (1998) and Shang (2007) all mentioned in their studies that E-mail increased the students' motivation. This is of great significance for the teaching of English writing, for in the present actual teaching one of the important factors the students lack is high motivation. In the present writing teaching, mainly the students write for exam, and the only reader of their writing is the teacher who will score their writings. Due to these reasons, students take writing as a boring activity. Another factor impeding students learning is their lack of confidence. Many

\footnotetext{
${ }^{2}$ Tokens refer to the individual occurrences of words; Types refer to distinct words within a text. For instance, in the sentence "You say either and I say either" there are 7 tokens and 5 types.
} 
students do not have enough confidence to express themselves, to communicate with others. The result of the present study showed us a good way to enhance their confidence. In the exit interview, two subjects stated as follows:

- My English is so poor, so I always do not speak and write. However, now I have much confidence in English when I found I could understand her and she also could understand me.

- Because of her (the E-mail partner) and the American movies I have seen (include "High School Musical"), I am more and more interested in English now. Though my English is still poor, I have confidence in myself.

\section{The Advantages and Problems}

Table 5 showed that most students agreed with the statements about the advantages, which means they perceived that E-mail exchange made their writing meaningful; they got a better understanding of the foreign culture; and they felt more relaxed writing with E-mail compared with sitting in the traditional classroom writing on the paper.

Having direct communication with native speakers and letting them, rather than instructors, be the information-givers should be strongly encouraged. Since culture exists in every native speaker's thoughts, conversations, and behaviors, students can learn culture from native speakers directly. While it's impossible for all the learners to communicate with native speakers face to face, E-mail may serve a feasible way to have direct and authentic communication. The students can openly ask native speakers about their values and life styles. Through direct interaction with the native speakers, learners are able to notice the unique characteristics of the target language culture.

Many of the previous studies mentioned that the students in E-mail group gained a deeper understanding about the foreign culture after the E-mail correspondence (Liaw \& Johnson, 2001; Jogan et al. 2001; Qi, 2006). Pan and Rong (2000) claimed E-mail exchange was a good way to teach students about culture. In fact, many subjects stated that they had known much more about American culture from their partners. The following statements are found in the interview:

- The American culture may be the most important thing that I've learnt.

- I know more differences between America and China, about education, environment and many other aspects.

- From my e-pal, I know some things about their lives and their culture.

- By writing to my pen-pal I've known more about America.

One interesting thing is that after the E-mail exchange a student even changed his opinion on the issue of going abroad. He stated like this: "About studying abroad, I change my mind now. Before, I think there is no need and it's just to get a diploma, but after chatting with the little American, I am shocked a lot and feel that there are so much I can't get in China and must go abroad to understand others' life philosophy if I want to contact with them. What's more, studying abroad means one can get a wider filed of vision."

Teachers are always looking for authentic material and communicative activity to make classroom teaching more real and attractive for their students. But now, when students have E-pals from another country, they feel the need to communicate clearly. E-mail is independent of time and place, which allows the students to communicate with people they like. With E-mail exchange activity, students can extend their learning beyond the four walls of the classroom.

All these advantages may make the students willing to write, and thus contribute to the improvement of their writing proficiency. According to Table 4, the biggest problem encountered by students was deficiency in vocabulary, with the mean as high as 4.42 , followed by poor expressing ability, low response, and cultural differences.

The students' statements in the exit interview confirmed the result obtained from the survey questionnaire. The following may be taken for example to support the point:

- The main problem I came across in this activity is that my English writing ability is really poor, my E-pal's English is much better than mine. I feel guilt.

- Waiting the letter in reply is what I like the least. And I can't express myself most of the time.

- The problem what I came across is that I don't know many words' meaning.

- When we talked to each other I found that my vocabulary is so little that sometimes I can't express myself.

- In the activity, the biggest problem is that I can't express my opinions clearly in many times and feel the lack of vocabulary. So I should recite more words and phrases. That's indeed a big problem to me.

Measures need to be taken to solve the above-mentioned problems. First, it's urgent to enlarge the students' vocabulary. Students should learn to use more strategies in accumulating vocabulary. Also reading may be a good way to enrich students' vocabulary and promote their writing skills. Stotsky (cited in Deng, 2000:28) stated, "Reading experience may be as critical a factor in developing writing ability in that reading enables students engage actively with new language and culture". Second, teachers should include culture into instruction. Cultural difference has become a main barrier impeding the successful communication across nations. Third, low response is another frequent complaint by the students. To overcome this problem, teachers of both sides need to encourage the students very well. And the teachers should be always ready to give the students a hand when they encounter problems.

\section{CONCLUSION}

Few studies have been conducted on E-mail and English learning, particularly English writing in China. The present study was one of the few studies to investigate the impact of E-mail on English learning in which the EFL learners communicate with native speakers in the target language. Both quantitative and qualitative data were collected for the 
current research. The following are the major findings of the study.

The results of the quantitative data indicated that the students who used E-mail and the students who did not use E-mail significantly differ in their English writing performance. Both quantitative and qualitative data showed that their writing ability got improved in aspects of content, language, vocabulary and organization, except for the mechanics.

According to the analysis of the qualitative data, E-mail was found to be able to motivate students, help in learning culture, involve them in authentic communication, promote the autonomy in learning, and enhance the students' confidence in writing.

Generally, the present study was well perceived by the participants. The results got from the questionnaire and exit interview showed that they were in favor of the E-mail exchange activity. Therefore, it can be concluded that applying E-mail appropriately will undoubtedly contribute a lot to EFL writing teaching.

In summary, the study indicated that E-mail can indeed be a beneficial supplement to the traditional classroom despite a few drawbacks. Roberts claims, "When the E-mail classroom connection processes are truly integrated into the ongoing structure of homework and classroom interaction, then the results can be educationally transforming" (Warschauer 1995:95). Therefore, teachers should attempt to integrate E-mail into the overall English education program in order to make full use of this new technology.

Although the findings of the study are largely positive, several limitations should be noted here. First, the present study was conducted to a small sample over a short period, and the sample was not randomly chosen due to practical difficulties. Second, the difficulty in conducting the study was not fully estimated. The firewall of American side was too picky, which prevented the communication from starting smoothly in the beginning of the study. Third, the discussion on the cooperation in the activity with the American teacher was not detailed enough. This led to the teacher's poor encouragement to the American students in replying letters, which possibly influenced the findings. Last, because the researcher was the students' instructor as well as interviewer, it is possible that they might have been hesitant to criticize the activity.

\section{REFERENCES}

[1] Belisle, R. (1996). E-mail activities in the ESL writing class. The Internet TESL Journal, 2/12.http://iteslj.org/Articles/Belisle-Email.html (accessed 15/06/2013).

[2] Choi, J. and Nesi, H. (1998). An account of a pilot key pal project for Korean children. English Language Teacher Education and Development (ELTED), 4/1: 21-45.

[3] Deng, X, L. (2000). Investigations on college students' writing ability in English and the implications. Unpublished Master's thesis, South-West China Normal University.

[4] Gu, P. Y., Cao, L. L. \& Xu, K. (1998). Internet-assisted English Teaching. Shanghai: Shanghai Foreign Language Education Press.

[5] Janda, T. (1995). Breaking the ice: E-mail dialogue journal introductions and responses. In M. Warschauer(Eds). Virtual Connections: Online Activities and Projects for Networking Language Learners. Honolulu, HI: University of Hawaii.

[6] Jogan, M. K., Heredia, Ana H. A., \& Gladys, M. (2001). Cross-cultural E-mail: providing cultural input for the advanced foreign language student. Foreign Language Annals, 34/4: 341-46.

[7] Liaw, M, L. \& Johnson, R. J. (2001). E-mail writing as a cross-cultural learning experience. System, 29/2: 235-51.

[8] Pan, B. X. \& Rong, J. (2000). Employing E-mail in the teaching of intercultural communication, Compute-assisted Foreign Language Education, 4, 30-33.

[9] Qi, Y. L. \& H, J. (2006). Using key pal activities to facilitate English writing teaching, China Modern Educational Facilities. 12, 50-52.

[10] Raimes, A. (1983). Techniques in Teaching Writing. New York: OUP.

[11] Rass, R. (2001). Integrating reading and writing for effective language teaching. English Teaching Forum, 39: 30-33.

[12] Shang, H, F. (2007). An exploratory study of E-mail application on FL writing performance Computer Assisted Language Learning, 20/1, 79-96.

[13] Warschauer, M. (1995). E-mail for English Teaching. Alexandria, VA: TESOL Publications.

Jiaxin Xing was born in 1981 in Linyi, Shandong province, P. R. China. He is a lecturer in Qufu Normal University. He got his master's degree in Wuhan University in China, majoring in applied linguistics. He has been a visiting scholar in Beijing Foreign Studies University (2012-2013). Now he is a PHD candidate in Beijing Normal University. He has been teaching English for more than ten years and published more than ten academic articles. His research interest includes writing feedback, task-based language teaching (TBLT), computer-assisted language learning (CALL), and teacher education, etc. He is now a member of Asian TEFL. 